\title{
WE43 BIOCOMPATIBLE ALLOY AFTER SEVERE PLASTIC DEFORMATION: STRUCTURE CHARACTERIZATION
}

\author{
Lenka KUNČICKÁ ${ }^{1}$, Petr KRÁL ${ }^{1}$, Jiří DVOŘÁK ${ }^{1}$, Radim KOCICH² \\ ${ }^{1}$ Institute of Physics of Materials, Academy of Science of Czech Republic, Brno, Czech Republic, EU, \\ kuncicka@ipm.cz \\ ${ }^{2}$ VSB-TU Ostrava, Ostrava, Czech Republic, EU, radim.kocich@vsb.cz
}

https://doi.org/10.37904/metal.2019.766

\begin{abstract}
The report presents results of the analyses of biocompatible WE $43 \mathrm{Mg}$-based alloy processed by friction stir processing (FSP) at two different rotational speeds of $400 \mathrm{rpm}$, and $1200 \mathrm{rpm}$. The structures were observed by scanning electron microscopy (SEM), electron backscattered diffraction (EBSD). Observations were primarily focused on characterizations of grains and textures; supplementary testing of mechanical properties was performed via tensile tests. The results of low angle grain boundaries fractions and grain sizes showed that both the processing methods led to significant grain refinement and recrystallization, the average grain diameter within the $1200 \mathrm{rpm}$ sample was less than $2 \mu \mathrm{m}$. Texture observations showed slight tendencies of the grains to align in the $\{0001\}\langle 10 \overline{1} 0\rangle$ and $\{0001\}\langle 11 \overline{2} 0\rangle$ preferential orientations, however, the maximum intensities were only about two times random. Supplementary tensile tests confirmed the positive effects of FSP on structures and properties of both the samples.
\end{abstract}

Keywords: Magnesium alloys, texture, scanning electron microscopy, X-ray diffraction

\section{INTRODUCTION}

The advantageous mechanical and physical properties make Mg-based alloys perspective solutions for demanding modern applications [1,2]. Due to their favourable biocompatibility, light weight, and low elastic modulus, some alloys are also bio-applicable $[3,4]$. Besides the positive effect on in-vivo corrosion resistance, additions of rare earth ( $R E$ ) elements were shown to increase formability, which is generally very low for pure $\mathrm{Mg}$, by reducing the critical resolved shear stress (CRSS) for non-basal slip systems [5]. RE such as Gd and $\mathrm{Nd}$ generally support grain refinement and improvement and homogenization of the mechanical properties, e.g. via formation of precipitates stable at a wide temperature range [6]. Similarly to $\mathrm{Nd}$, yttrium supports texture randomization and activation of non-basal slip systems, and increases both, formability and final strength [7]. It also supports creep resistivity, as does also e.g. thorium and silver [8].

The formability of Mg-based alloys can also be enhanced by processing at elevated temperatures (higher than $\sim 250^{\circ} \mathrm{C}$ ) [8], or by utilization of specialized deformation technologies. Methods of severe plastic deformation (SPD), such as equal channel angular pressing - ECAP [9] and its modifications [10], twist extrusion (TE) [11], etc., are favourable not only for imparting significant grain refinement and enhancing the final properties of materials, but also for the ability to process materials with low formability [12-14]. From the grain refinement viewpoint, the most effective SPD methods are high pressure torsion HPT [15] and friction stir processing (FSP). Several reports on the effects of FSP on Mg-based alloys have been published [16-20], but they are scarce.

This study presents the results of the investigation of a cast and solution treated Mg-4Y-3Nd (WE43) alloy processed via rotary swaging (RS) and subsequently via friction stir processing (FSP). RS is a versatile intensive plastic deformation process which enables to reduce the diameters of solid and hollow axisymmetric products by a repeated action of rotating swaging dies [21]. It contributes to structure homogenization, grain refinement, and enhancement of the final properties. The structures were studied via scanning electron 
microscopy; the analyses primarily focused on grains and texture characterization. Structure observations were supplemented with tensile testing of mechanical properties.

\section{EXPERIMENT}

WE43 alloy was cast into a mould with the diameter of $40 \mathrm{~mm}$ and length of $80 \mathrm{~mm}$, homogenization annealed, processed via RS, heat treated by T4 heat treatment - 8 hours' dwell at $520^{\circ} \mathrm{C}$ followed by quenching (similar to $[4,6])$ - and subsequently subjected to $400 \mathrm{rpm}$ and $1200 \mathrm{rpm}$ FSP. The final reduction ratio during RS was 1.20 .

After swaging (RS) and solution treatment (ST), samples with $40 \times 20 \times 20 \mathrm{~mm}$ dimensions were cut using electric discharging machine, polished, and subjected to FSP processing at the traverse rate of $60 \mathrm{~mm} \cdot \mathrm{min}^{-1}$ and the rotational speeds of $400 \mathrm{rpm}$ and $1200 \mathrm{rpm}$. The conical friction tool with a pin with $3 \mathrm{~mm}$ in length and diameter varying between $6 \mathrm{~mm}$ and $4 \mathrm{~mm}$ equipped with a flat shoulder with $15 \mathrm{~mm}$ in diameter was made of a tool steel (set up similar as e.g. in refs. [18,22]).

After FSP and final quenching in water, samples taken for structure analyses in the direction of friction tool movement were mechanically ground and electrolytically polished. The structures of the FSP-processed samples, as well as the sample after rotary swaging and solution treatment (RS(ST)) were scanned using a Tescan Lyra 3 SEM device equipped with an electron backscatter diffraction (EBSD) detector. The scans acquired with the step of $0.25 \mu \mathrm{m}$ were evaluated using OXFORD Instruments [23] and LEM3 Laboratories [24] software. The textures were evaluated in the direction perpendicular to the direction of friction tool movement with $20^{\circ}$ maximum misorientation. The $10 \mathrm{~mm}$ long samples for tensile testing with $2 \times 4 \mathrm{~mm}$ crosssections were cut in the direction parallel to the direction of friction tool movement with an electric discharging machine. Tensile tests were performed at room temperature with the strain rate of $10^{-3} \mathrm{~s}^{-1}$ using a Zwick machine.

\section{RESULTS AND DISCUSSION}

\subsection{Grains characterization}

The mean grain diameter for the RS(ST), $400 \mathrm{rpm}$, and $1200 \mathrm{rpm}$ sample was $58.5 \mu \mathrm{m}, 4.2 \mu \mathrm{m}$, and $1.8 \mu \mathrm{m}$, respectively (Figure 1a to 1c). The $1200 \mathrm{rpm}$ FSP rate led to the formation of microstructure the average grain size within which approached the ultra-fine (UF) level, $\sim 18 \%$ of the grains were smaller than $1 \mu \mathrm{m}$. The significant grain refinement, especially after $1200 \mathrm{rpm}$, can be explained by the combined effects of dynamic recrystallization and presence of $\mathrm{Nd}$ and $\mathrm{Y}$ elements supporting grain boundary pinning and UF grains formation [1,25]. Similar phenomenon was observed by Vargas et al. [19] for a ZKX50 alloy with an addition of $\mathrm{Zr}$, the average grain size for which after FSP processing by $1000 \mathrm{rpm}$ was $\sim 1 \mu \mathrm{m}$.

a)

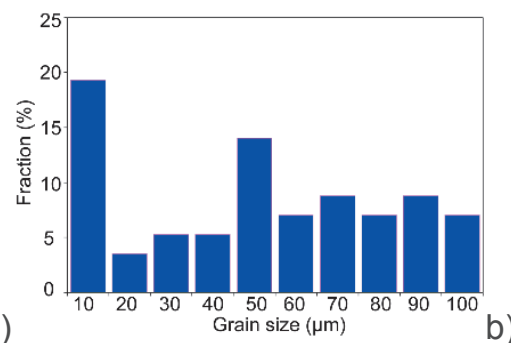

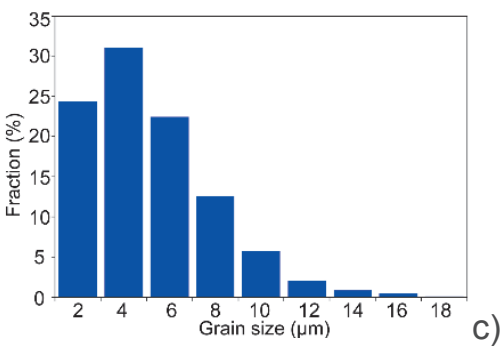

)

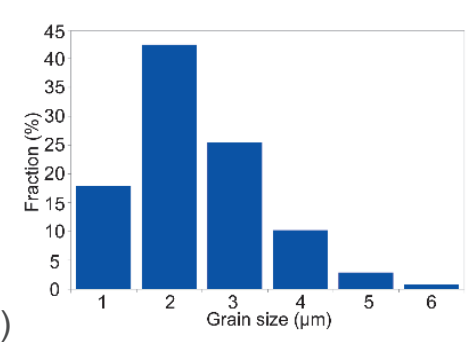

$(d)$

The grain boundaries analyses showed that the RS(ST) sample featured a vast majority of high angle grain boundaries (HAGBs), which is typical for annealed materials (not shown here). After 400 RMP of FSP, the 
fraction of low angle grain boundaries (LAGBs) increased to approximately $11 \%$ (Figures 2a, 2b), which points to the development of substructure by the effect of the severe imposed strain introducing accumulation of structure defects, such as dislocations, which cluster into tangles and cells, and form dislocation walls and eventually LAGBs [26]. As evident from Figures $\mathbf{2 c}$ and $\mathbf{2 d}$, processing at 1200 RMP introduced a fraction of LAGBs similar to processing at $400 \mathrm{rpm}$, i.e. $11 \%$.

a)

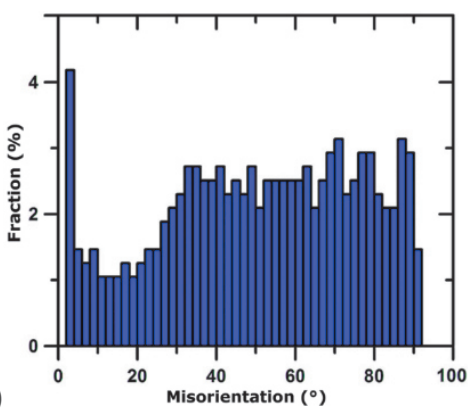

b)

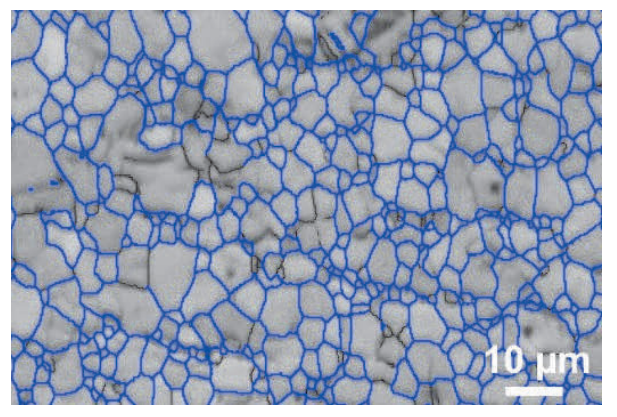

d)

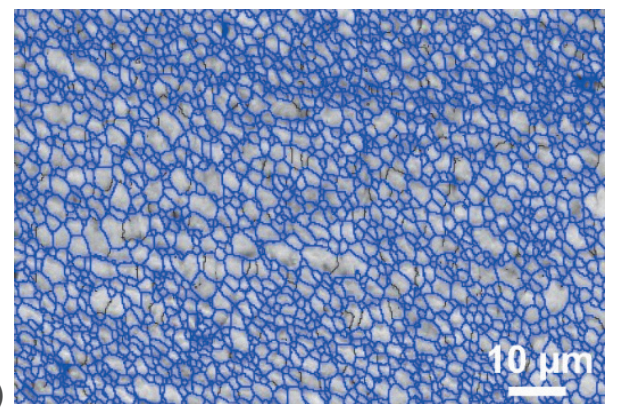

Figure 2 Grain boundaries misorientations distributions for samples: 400 rpm (a); 1200 rpm (c); EBSD scans with HAGBs highlighted in blue colour: 400 rpm (b); 1200 rpm (d).

The results indicate that FSP processing at $400 \mathrm{rpm}$ already introduced sufficient energy to impart recrystallization within the structure. Nevertheless, the increase in FSP rate up to $1200 \mathrm{rpm}$ resulted in increase in the imposed energy and in the real processing temperature, too. After the critical level of accumulated energy is reached, recrystallization introduces formation of grains characterized with HAGBs, which decreases the volume fraction of LAGBs [26]. However, HAGBs featuring high energy are not thermodynamically stable. By this reason, the structure has the tendency to decrease the internal energy via formation of new dislocation tangles, dislocation cells and walls, and subsequent formation of new LAGBs if activated e.g. via increasing the FSP rate [27]. These phenomena resulted in the comparable fractions of LAGBs for the $400 \mathrm{rpm}$ and 1200 rpm samples despite the finer grains and higher fraction of recrystallized grains (as further proven in Section 3.2) within the 1200 sample.

\subsection{Texture}

The textures for the RS(ST), $400 \mathrm{rpm}$, and $1200 \mathrm{rpm}$ samples were evaluated with the emphasis on the preferential orientations and recrystallized fractions. Figure $3 a$ to $3 c$ show pole figures (PF) depicting recrystallized grains for RS(ST), $400 \mathrm{rpm}$, and $1200 \mathrm{rpm}$ samples, respectively. The colours in the PFs characterize the individual growing grains, from blue for the new smallest recrystallized grains, through green for the growing ones, to red for the largest grown grains.

As can be seen, the RS(ST) sample featured randomly scattered grains with no preferential orientations (Figure 3a). Processing at $400 \mathrm{rpm}$ imparted significant grain refinement. The fresh new nucleated grains depicted as blue dots in Figure $\mathbf{3 b}$ did not exhibit any preferential orientation. However, the growing grains depicted as green and red dots exhibited the tendency to form the $\{0001\}\langle 10 \overline{1} 0\rangle$ and $\{0001\}\langle 11 \overline{2} 0\rangle$ preferential 
orientations, but the total texture intensities were not substantial (slightly higher than 2 times random). The PF depicting texture characteristics for the $1200 \mathrm{rpm}$ sample is shown in Figure 3c. The structure also evidently underwent massive dynamic recrystallization and grain refinement, no secondary grain growth connected with post-process grains reorientation was observed. FSP processing caused the base material to rapidly melt and subsequently cool with the rate sufficient for formation of fine-grained structure exhibiting both the $\{0001\}\langle 10 \overline{1} 0\rangle$ and $\{0001\}\langle 11 \overline{2} 0\rangle$ preferential orientations in similar intensities. Mutual correlation of the Figures imparts the supposition that the growing grains had the tendency to align along the $\{0001\}\langle 11 \overline{2} 0\rangle$ preferential orientations at first, and later on, as they continued to grow, tended to acquire the $\{0001\}\langle 10 \overline{1} 0\rangle$ orientation. The very low (neglectable) maximum intensities of the preferential orientations demonstrate the favourable influence of the $\mathrm{Nd}$ and $\mathrm{Y}$ alloying elements on texture randomization. Texture randomisation invoked by RE additions within Mg-based biocompatible alloys was reported to support homogenization of mechanical and corrosion properties and contribute to lower anisotropy as regards the compression and tension loads, which influences positively the fatigue life of the final product [28].
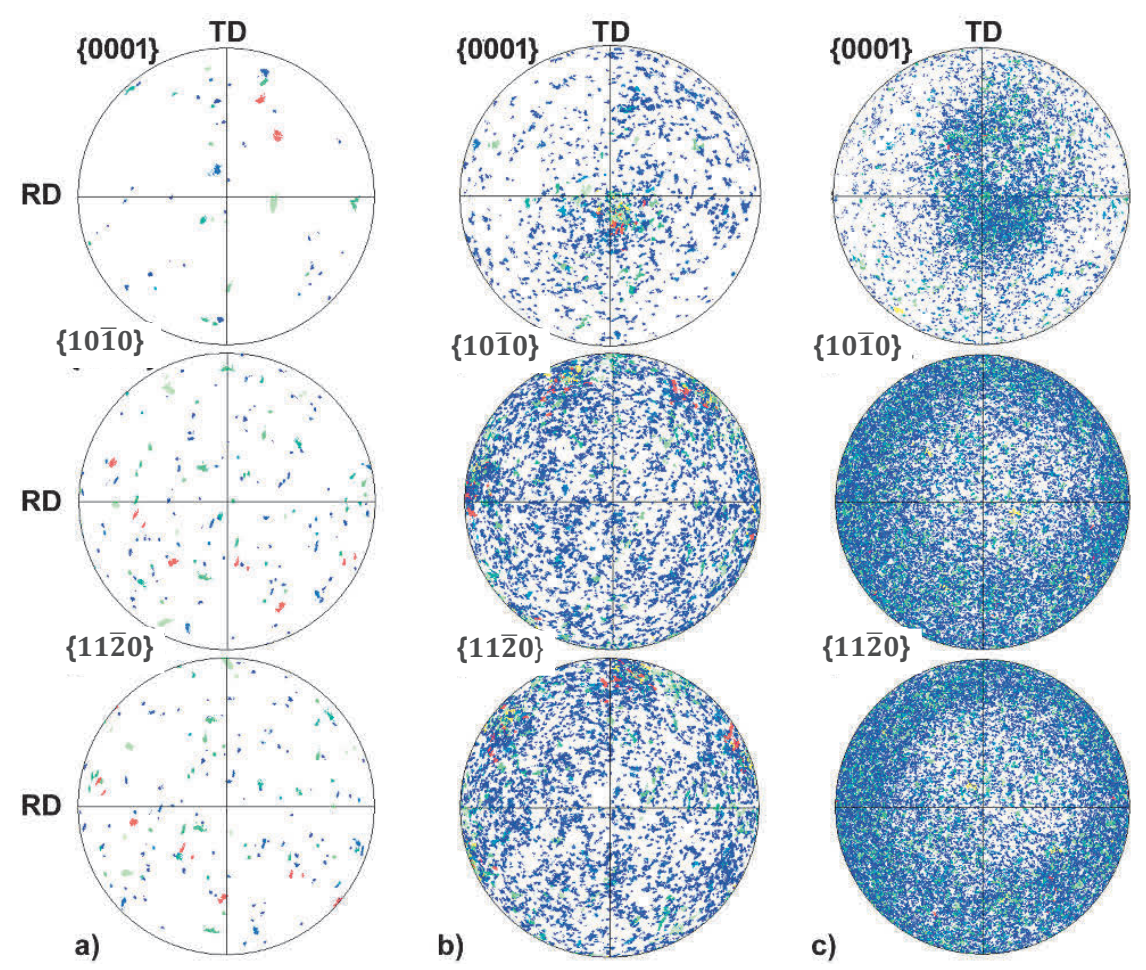

Figure 3 Pole figures emphasizing grains orientations in relation with grain growth for samples: (a) RS(ST); (b) 400 rpm; (c) $1200 \mathrm{rpm}$

\subsection{Tensile tests}

The ultimate tensile strength (UTS) of the as-cast material was quite low, only $142 \mathrm{MPa}$. However, subsequent swaging and solution treatment resulted in the increase in UTS to $201 \mathrm{MPa}$, the processing also increased the elongation to failure, from $3.8 \%$ for as-cast material to $5.8 \%$. RS is known for its favourable influence on grain refinement and fragmentation of large precipitates [29] and its positive effects on enhancement of mechanical properties were also documented by others. For example, Wang et al. [30] reported the UTS to increase up to $350 \mathrm{MPa}$ for a hot rotary swaged and subsequently aged WE43 alloy.

The final stress-strain curves for the materials processed via FSP are depicted in Figure 4. Evidently, plasticity (elongation to failure) increased significantly for both the processed samples and FSP processing by $1200 \mathrm{rpm}$ resulted in the increase in UTS to almost $280 \mathrm{MPa}$. The advantageous combination of high UTS and favourable 
elongation of more than $11 \%$ recorded for the $1200 \mathrm{rpm}$ sample can primarily be attributed to the fine recrystallized grains and almost random grains orientations ensuring uniform properties throughout the material [31].

The comparison of the plastic properties for the RS(ST) and 400 rpm and $1200 \mathrm{rpm}$ samples reveals that the plasticity was the lowest for the RS(ST) sample. This sample featured not only significantly larger grains, but also precipitated particles introduced by the solution treatment which acted as obstacles for dislocations movement during tensile loading under cold conditions. This resulted in lower plasticity when compared to the FSP samples [32], the processing of which imparted dissolution of most of the precipitates into solid solution, which enhanced plasticity and also increased the UTS [27].

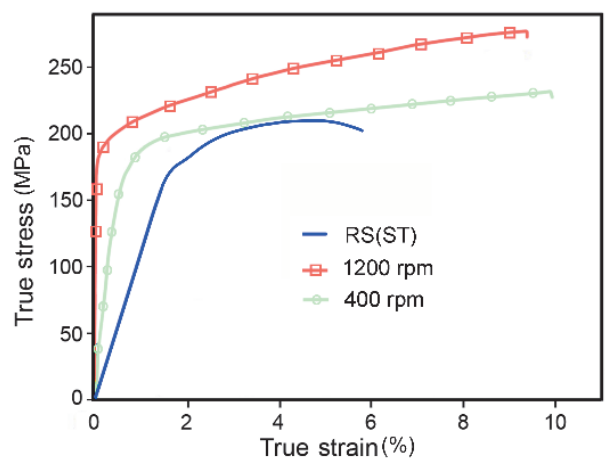

Figure 4 Stress-strain curves for RS-ST and FSP-processed materials

\section{CONCLUSION}

The WE43 Mg-based alloy was cast, subjected to rotary swaging followed by solution treatment, and finally processed via friction stir processing (FSP) at the rotational speeds of $400 \mathrm{rpm}$ and $1200 \mathrm{rpm}$. FSP introduced significant grain refinement, the $1200 \mathrm{rpm}$ sample exhibited fine grained structure with the average grain size smaller than $2 \mu \mathrm{m}$. Both the processed samples featured new recrystallized grains with no prevailing preferential orientation, significantly improved strength of more than 200 and $250 \mathrm{MPa}$, respectively, and the maximum elongation of more than $10 \%$. Suffice to say, both the samples treated at $400 \mathrm{rpm}$ and $1200 \mathrm{rpm}$ exhibited substantial grain refinement and texture randomization, which imparts promising application of the WE43 alloy processed via rotary swaging and subsequent FSP at room temperature or at slightly elevated temperatures, such as within the human body.

\section{AKNOWLEDGEMENTS}

This research was financially supported by the Ministry of Education, Youth and Sports of the Czech Republic under the project m-IPMinfra (CZ.02.1.01/0.0/0.0/16_013/0001823) and the equipment and the base of research infrastructure IPMinfra were used during the research activities.

\section{REFERENCES}

[1] POURBAHARI, Bita, MIRZADEH, Hamed and EMAMY, Massoud. The effects of grain refinement and rare earth Intermetallics on mechanical properties of as-cast and wrought magnesium alloys. Journal of Materials Engineering and Performance. 2018. vol. 27, pp. 1327-1333.

[2] SEETHARAMAN, R., LAVANYA, B., NIHARIKA, Nutan, and THYAGARAJAN, P. Development and Performance Validation of Engine oil Pump for Passenger Cars Using Magnesium Alloy. Materials Today: Proceedings. 2017. vol. 4, pp. 6743-6749.

[3] GU, Xue-Nan and ZHENG, Yu-Feng. A review on magnesium alloys as biodegradable materials. Frontiers of Materials Science in China. 2010. vol. 4, pp. 111-115.

[4] KOCICH, Radim, KUNČICKÁ, Lenka, KRÁL, Petr and LOWE, Terry C. Texture, deformation twinning and hardening in a newly developed Mg-Dy-Al-Zn-Zr alloy processed with high pressure torsion. Materials and Design. 2016. vol. 90, pp. 1092-1099.

[5] IMANDOUST, A., BARRETT, C. D., AL-SAMMAN, T., INAL, K. A., and EL KADIRI, H. A review on the effect of rare-earth elements on texture evolution during processing of magnesium alloys. Journal of Materials Science. 2017. vol. 52, pp. 1-29. 
[6] KUNČICKÁ, Lenka, KOCICH, Radim. Comprehensive Characterisation of a Newly Developed Mg-Dy-Al-Zn-Zr Alloy Structure. Metals. 2018. vol. 8, pp. 73-88.

[7] REN, Lingbao, ZHOU, Mingyang, ZHANG, Yuwenzi, BOEHLERT, Carl J., and QUAN, Gaofeng. Effect of 0.4 wt\% yttrium addition and heat treatment on the high-temperature compression behavior of cast AZ80. Journal of Materials Science. 2019. vol. 54, pp. 5757-5772.

[8] RUSSELL, Alan and LEE, Kok Loong. Structure-Property Relations in Nonferrous Metals. 1st Ed. John Wiley \& Sons, Inc., 2005, p. 133.

[9] NAIK, Gajanan M., NARENDRANATH, S. and SATHEESH KUMAR, S. S. Effect of ECAP Die Angles on Microstructure Mechanical Properties and Corrosion Behavior of AZ80 Mg Alloy. Journal of Materials Engineering and Performance. 2019. vol. 28, pp. 2610-2619.

[10] KOCICH, Radim, KUNČICKÁ, Lenka and MACHÁČKOVÁ, Adéla. Twist Channel Multi-Angular Pressing (TCMAP) as a method for increasing the efficiency of SPD. In IOP Conference Series: Materials Science and Engineering. Metz: Université de Lorraine, 2014, vol. 63, 012006.

[11] VAKILI NOOR, S., EIVANI, Ali Reza, JAFARIAN, H. R. and MIRZAEI, M. Inhomogeneity in microstructure and mechanical properties during twist extrusion. Materials Science and Engineering A. 2016. vol. 652, pp. 186-191.

[12] KOCICH, Radim, GREGER, Miroslav and MACHÁČKOVÁ, Adéla. Finite element investigation of influence of selected factors on ECAP process. In METAL 2010: 19th International Metallurgical and Materials Conference. Ostrava: TANGER, 2010, pp. 166-171.

[13] LEI, Weiwei, LIANG, Wei, WANG, Hongxia and SUN, Yanhao. Effect of annealing on the texture and mechanical properties of pure Mg by ECAP at room temperature. Vacuum. 2017. vol. 144, pp. 281-285.

[14] LUKÁČ, Pavel, KOCICH, Radim, GREGER, Miroslav, PADALKA, Oksana and SZARAZ, Zoltán. Microstructure of AZ31 and AZ61 Mg alloys prepared by rolling and ECAP. Kovove Materialy. 2007. vol. 45, pp. 115-120.

[15] XU, Jie, WANG, Xinwei, SHIROOYEH, Mahmood, XING, Guangnan, SHAN, Debin, GUO, Bin and LANGDON, Terence G. Microhardness, microstructure and tensile behavior of an AZ31 magnesium alloy processed by highpressure torsion. Journal of Materials Science. 2015. vol. 50, pp. 7424-7436.

[16] WANG, Yaobin, HUANG, Yongxian, MENG, Xiangchen, WAN, Long and FENG, Jicai. Microstructural evolution and mechanical properties of MgZnYZr alloy during friction stir processing. Journal of Alloys and Compounds. 2017. vol. 696, pp. 875-883.

[17] DEEPAN, M., PANDEY, Chandan, SAINI, N., MAHAPATRA, M. M. and MULIK, R. S. Estimation of strength and wear properties of $\mathrm{Mg} / \mathrm{SiC}$ nanocomposite fabricated through FSP route. Journal of the Brazilian Society of Mechanical Sciences and Engineering. 2017. vol. 39, pp. 4613-4622.

[18] KUMAR, Nileash, MISHRA, Rajiv S., DAHOTRE, N. B., BRENNAN, Raymond E., DOHERTY, Kevin J. and CHO, Kyu C. Effect of friction stir processing on microstructure and mechanical properties of laser-processed Mg-4Y3Nd alloy. Materials and Design. 2016. vol. 110, pp. 663-675.

[19] VARGAS, Margarita Maria, LATHABAI, Sri, UGGOWITZER, Peter J., QI, Y., ORLOV, Dmytro and ESTRIN, Yuri. Microstructure, crystallographic texture and mechanical behaviour of friction stir processed Mg-Zn-Ca-Zr alloy ZKX50. Materials Science and Engineering A. 2017. vol. 685, pp. 253-264.

[20] LIU, Gang MA, Zhenduo, WEI, Guobing, XU, Tiancai, XI, Zhang, YANG, Yan, XIE, Weidong and PENG, Xiaodong. Microstructure, tensile properties and corrosion behavior of friction stir processed Mg-9Li-1Zn alloy. Journal of Materials Processing Technology. 2019. vol. 267, pp. 393-402.

[21] KOCICH, Radim, KUNČICKÁ, Lenka, KRÁL, Petr and STRUNZ, Pavel. Characterization of innovative rotary swaged Cu-Al clad composite wire conductors. Materials and Design. 2018. vol. 160, pp. 828-835.

[22] ASADI, Parviz, MAHDAVINEJAD, R. A. and TUTUNCHILAR, Saman. Simulation and experimental investigation of FSP of AZ91 magnesium alloy. Materials Science and Engineering A. 2011. vol. 528, pp. 6469-6477.

[23] OXFORD INSTRUMENTS. Providing leading-edge tools for SEM, TEM \&FIB - Nanoanalysis. 2018. Available at: https://nano.oxinst.com/.

[24] BEAUSIR, Benoit and FUNDENBERGER, Jean-Jacques. Analysis Tools for Electron and X-ray diffraction, ATEX - software. 2017. Available at: www.atex-software.eu. 
[25] LIU, Yu, ZHOU, Jixue, LIU, Yunteng and TANG, Shouqiu. Effect of Rare-Earth Element Y on the Microstructure and Mechanical Properties of the Mg-6.0wt.\%Zn-0.5wt.\%Zr Alloy. Materials Science Forum. 2017. vol. 898, pp. 91-96.

[26] HUMPHREYS, John F. and HETHERLY, M. Recrystallization and Related Annealing Phenomena. Elsevier Ltd, 2004, p. 163.

[27] VERLINDEN, Bert, DRIVER, Julian, SAMAJDAR, Indradev and DOHERTY, Roger D. Thermo-mechanical processing of metallic materials. Elsevier, 2007, p. 167.

[28] HÄNZI, Anja C., GERBER, Isabel, SCHINHAMMER, Michael, LÖFFLER, Jörg F. and UGGOWITZER, Peter J. On the in vitro and in vivo degradation performance and biological response of new biodegradable $\mathrm{Mg}-\mathrm{Y}-\mathrm{Zn}$ alloys. Acta Biomateialia. 2010. vol. 6, pp. 1824-1833.

[29] GAN, W. M., HUANG, Y. D., WANG, R., WANG, G. F., SRINIVASAN, A., BROKMEIER, H. G., SCHELL, N., KAINER, K. U. and HORT, N. Microstructures and mechanical properties of pure Mg processed by rotary swaging. Materials and Design. 2014. vol. 63, pp. 83-88.

[30] WANG, Chang, YU, Zhentao, CUI, Yajun, YU, Sen, MA, Xiqun and LIU, Hanyuan. Effect of Hot Rotary Swaging and Subsequent Annealing on Microstructure and Mechanical Properties of Magnesium Alloy WE43. Metal Science and Heat Treatment. 2019. vol. 60, pp. 777-782.

[31] RAPP, Dennis, SAJADI, Seyedsaeid, MOLNAR, David, BINKELE, Peter, WEBER, Ulrich, HOCKER, Stephen, MORA, Alejandro and SEEGER, Joerg. Multiscale Simulation of Precipitation in Copper-Alloyed Pipeline Steels and in Cu-Ni-Si Alloys. In: SCHMAUDER, S. (Ed.). Handbook of Mechanics of Materials. Springer Singapore, 2018, chapter 1,pp. 1-41.

[32] LI, Jin, ZHANG, Da-Tong, CHAI, Fang and ZHANG, Wen. Microstructures and mechanical properties of WE43 magnesium alloy prepared by friction stir processing. Rare Metals. pp. 1-6. doi:10.1007/s12598-014-0306-3. 